\title{
A quem serve a comunicação? Brasil, desigualdades e luta de classes
}

Rafael Grohmann

Doutorando em Ciências da Comunicação pela Universidade de São Paulo (USP). Professor do Mestrado Profissional em Jornalismo do FIAM-FAAM - Centro Universitário e do curso de Jornalismo da Faculdade Cásper Líbero.

E-mail:rafael-ng@uol.com.br

Resumo: O livro A tolice da inteligência brasileira, de Jessé Souza, nos coloca a pensar quais as contribuições dos intelectuais brasileiros e da comunicação na luta de classes, na reprodução das desigualdades e nos projetos de país. Por uma Ciência da Comunicação não estéril, urge incorporar reflexões sobre a realidade brasileira.

Palavras-chave: Brasil; comunicação; classes; desigualdade.
Abstract: The book "A tolice da inteligência brasileira", by Jessé Souza, make us think about the contributions of Brazilian communication researchers to the class struggle, to the reproduction of inequalities and to the country's projects. For a non-sterile communication science it is urgent to include reflections on Brazilian reality.

Keywords: Brazil; communication; classes; inequality.

Com a hiperespecialização das ciências, muitas vezes tendemos a focar nossos esforços teóricos exclusivamente em nossas linhas de pesquisa nos programas de pós-graduação. Um dos riscos é, então, justamente a falta de compreensão de uma realidade mais ampla, envolvendo uma dimensão de país. Afinal, produzimos ciência com quais finalidades? A área de Comunicação e Educação não promete para si mesma uma pretensa "neutralidade axiológica"1, coloca-se em prol de uma transformação social, em resposta aos momento de "financeirização da comunicação" 2 . E é com o intuito de contribuir para a maior reflexão sobre o contexto brasileiro que trazemos o mais recente livro publicado pelo sociólogo Jessé Souza: A tolice da inteligência brasileira ${ }^{3}$.

Livro de divulgação dos pensamentos desenvolvidos, sobretudo, na última década, Souza, logo de cara, afirma que uma linguagem hermética ajuda a contribuir para a reprodução da desigualdade, evitando que grande parcela da população tenha acesso ao conhecimento que circula nos campos científicos. $\mathrm{O}$ conhecimento, então, deve ser visto como "arma de combate". A partir disso, o

1. SCHNEIDER, Marco. Ética e epistemologia: alerta contra a neutralidade axiológica na pesquisa em comunicação contemporânea. Revista Matrizes, v. 7, n. 2, jul./ dez. 2013, pp. 11-27.

2. SODRÉ, Muniz. A Ciência do Comum: Notas para o método comunicacional. Petrópolis: Vozes, 2014.

3. SOUZA, Jessé. A tolice da inteligência brasileira: Ou como o país se deixa manipular pela elite. São Paulo: Casa da Palavra, 2015. 
4. Idem. A modernização seletiva: Uma reinterpretação do dilema brasileiro. Brasília: Ed. UnB, 2000.

5. Idem. A construção social da subcidadania. Belo Horizonte: Ed. UFMG, 2003.

6. Idem. A invisibilidade da desigualdade brasileira. Belo Horizonte: Ed. UFMG, 2006.

7. Idem. A ralé brasileira: Quem é e como vive. Belo Horizonte. Ed. UFMG, 2009.

8. Idem. Os batalhadores brasileiros: Nova classe média ou nova classe trabalhadora? Belo Horizonte: Ed. UFMG, 2010.

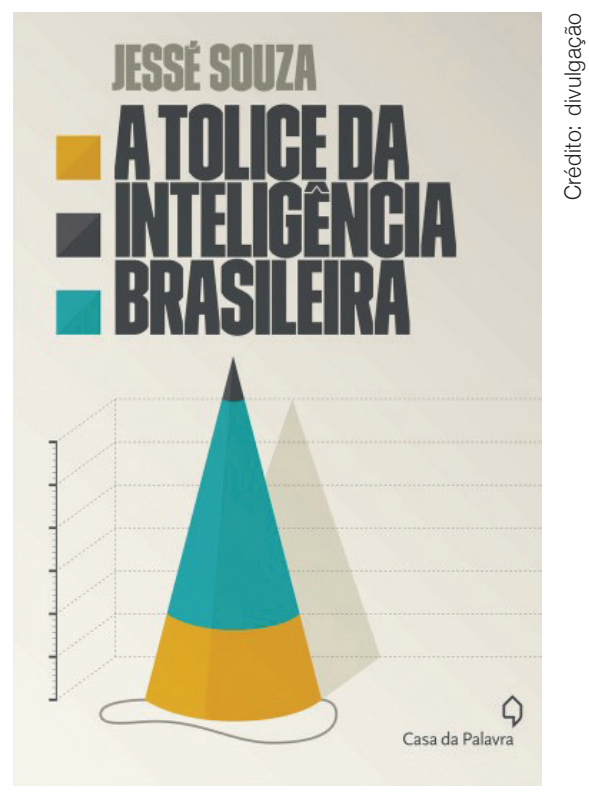

intuito principal da obra é desconstruir certa ideia dominante no pensamento social brasileiro, principalmente no que se refere às desigualdades, ao papel do Estado e do mercado.

Na trajetória de Jessé Souza, esse debate tem início na obra Modernização seletiva $a^{4}$ - onde ele se pergunta se o Brasil teria mesmo valores considerados "pré-modernos" - passando por A construção social da subcidadania", em que traz as contribuições de Pierre Bourdieu, Charles Taylor e Axel Honneth, e os livros com os resultados de exaustivas pesquisas empíricas, A invisibilidade da desigualdade brasileira ${ }^{6}$, A ralé brasileira ${ }^{7}$ e Os batalhadores brasileiros ${ }^{8}$. Trata-se, então, de um resumo desse caminho.

A linguagem contundente é notada desde o título, que também está na forte crítica direcionada a autores como Gilberto Freyre, Sérgio Buarque de Hollanda e Roberto da Matta. Souza afirma que eles culturalizam a teoria social e transformam em diferenças o que são desigualdades. Dessa forma, esses autores contribuiriam para legitimar o mito de o Brasil ser uma exceção frente aos outros, principalmente os ditos "desenvolvidos". Essa modernidade seletiva, articulando questões de patrimonialismo e personalismo, ajudariam a justificar um Brasil dito pré-moderno e de singularidade cultural. Souza analisa que o mito da democracia racial e a positivação da mestiçagem ajudam a encobrir desigualdades sob o manto de um país sem conflitos, assim, auxiliando no processo de naturalização da luta de classes.

Nessa narrativa de um país singular, culturalmente atrasado e sem fricções, o Estado seria patrimonialista e "obeso" - contribuição também de Raymundo Faoro - frente a um mercado "pulsante", e que traria uma maior racionalidade aos processos econômicos e políticos. Dessa forma, o Brasil é tomado como um território onde predominam as emoções, os afetos e os corpos frente ao cálculo e à racionalidade ascética da cultura norte-americana, por exemplo, 
que funcionaria "sem jeitinho". Jessé Souza, então, critica a temática da singularidade brasileira, pois o Brasil não é a exceção, mas a regra na sociedade capitalista em escala global, ou seja, o país deve ser compreendido a partir de um sistema, principalmente em tempos de financeirização.

Essa narrativa culturalista, para Jessé Souza, funciona como uma ideologia que permite legitimar privilégios, que são, ao mesmo tempo, teóricos e práticos, ajudando a manter hegemonias tanto na ciência quanto na circulação dos discursos na sociedade, de maneira a colocar todos os méritos na conta do indivíduo - a ideologia da meritocracia, com os privilégios sociais transformados em capacidades inatas ao indivíduo - e o Estado sendo visto como ineficaz, como uma figura de um país atrasado. Essa demonização do Estado atua como resultado da percepção de que tudo é corrupção quando se trata do Estado, e a salvação está nos méritos do mercado, que poderiam ajudar a modernizar o Brasil, como se corrupção não houvesse em outros lugares, por exemplo, e como se o corruptor não fosse o mercado. Isto é, há, ao mesmo tempo, um discurso de reiteração de que o país é diferente de todo o mundo, com processos políticos e sociais singulares, e, por outro lado, compara-se o Brasil a outras sociedades como a norte-americana, desconsiderando-se também as conexões financeiras, políticas e culturais entre o "local" e o "global".

Para Souza ${ }^{9}$, "a realidade social não é visível a olho nu, o que significa que o mundo social não é transparente a nossos olhos”, e esses intelectuais hegemônicos contribuiriam para a permanência da ocultação dessa realidade, e "as categorias científicas são utilizadas "por debaixo do pano""10, como uma ciência tornada mera ideologia.

Contudo, podemos notar no autor uma concepção de ideologia próxima à de "falsa consciência" e menos de algo constitutivo da realidade concreta e material, isto é, como se a ideologia se desse somente a partir de uma falsificação da realidade, sendo que, como já afirmam Bakhtin/Volochinov"11, é impossível separar os signos das ideologias. Na ciência, também se materializam as lutas de classes, é um campo de batalha. O tom do texto de Jessé Souza dá a crer que todos os outros são "ideólogos" e "falsificadores da realidade" e ele, iluminado, ajudaria o leitor a "desvelar toda a verdade" e "deixar de ser tolo da inteligência brasileira". Trata-se de uma concepção de ciência próxima à weberiana, em que "ciência" e "política" seriam eixos completamente distintos ${ }^{12}$. Ora, esse tom contribui mais para o maniqueísmo que para a construção de um olhar mais complexo para a ciência e para a realidade.

A despeito disso, podemos pensar: qual o papel da mídia ao reproduzir as representações dominantes sobre o país, dissimulando as lutas de classes e colocando as instituições públicas como mal geridas por um Estado incompetente em prol de um mercado virtuoso e eficiente? Mais: que papel tem os sujeitos ligados à Comunicação e Educação em pensar e praticar formas de resistência a essa hegemonia midiática?

Como podemos ver, não podemos desvincular a explicação sobre o país sem compreender a questão das classes.
9. Idem, 2015, p. 9.

10. Idem, p. 20.

11. BAKHTIN, Mikhail (VOLOCHINOV). Marxismo e Filosofia da Linguagem: Problemas fundamentais do método sociológico na ciência da linguagem. São Paulo: Hucitec, 2010.

12. Não se trata de negar a distinção entre ciência e política, mas mostrar como a linhagem argumentativa do autor segue a visão weberiana. 
O homem cordial não tem classe social, mesmo em um país tão desigual como o Brasil sempre foi. Ou seja, desde o início essa noção esconde conflitos sociais de toda espécie e cria um ser "genérico" que existe unicamente para ser contraposto ao "protestante ascético" como símbolo da cultura norte-americana ${ }^{13}$.

Contudo, como o autor enxerga a questão das classes? Principalmente a partir de Bourdieu, tendo como centrais os conceitos de "capital cultural" e "violência simbólica". Por um lado, trata-se de enfatizar que há formas de dominação e desigualdades não só e puramente a partir do campo econômico, e podemos incluir aí a comunicação, ou seja, como a legitimação e a reprodução de privilégios possui outros fatores. Porém, ao enfatizar demasiadamente o "simbólico" e o "cultural", Souza acaba por: a) dar pouco lugar às lutas e aos conflitos; b) obnubilar por completo o "econômico", tratado com desprezo a partir da pecha de "economicismo". Coloca, então, no mesmo balaio a perspectiva liberal e a marxista, que seriam, em sua visão, economicistas por excelência. Podemos notar, então, que há uma visão reducionista e equivocada do autor em relação a Marx.

Classe, para Marx, nunca foi sinônimo apenas de renda. Lugar na produção não significa somente a questão econômica. Considerar a realidade concreta e material não é sinônimo somente de dinheiro no bolso, mas de toda a vida cotidiana, incluída também a cultura. Como diz Eagleton"14, "o capitalismo, e não o marxismo, é que é economicamente reducionista. É o capitalismo que acredita na produção pela produção, no sentido mais estreito do termo 'produção"'. Pois a luta de classes não se reduz a fatores econômicos: "é sintomático que falemos de classes sociais, e não de classes econômicas"15. Um autor que poderia ajudar Jessé Souza a se livrar de uma visão rasa do marxismo é Raymond Williams, que, de forma brilhante, mostra como não há análise dialética sobre a sociedade que prescinda da questão da cultura, e como economia e cultura são questões interligadas. Tratar, portanto, o marxismo como economicista (e, portanto, desconsiderá-lo) e centrar toda a análise em questões como "capital cultural" e "violência simbólica" é cair em um mesmo erro antidialético. Como afirma Eagleton, a concepção de produção em Marx é em sentido mais "generoso" que o usual, relacionando-se à autorrealização humana, não se reduzindo a tratores e turbinas. "A produção que considerava importante se aproximava mais da arte do que da montagem de rádios transistores ou do abate de ovelhas" ${ }^{\prime 16}$.

Com isso, Souza acaba por mostrar uma leitura superficial da obra de Marx (e de seu legado), por exemplo, ao dizer que as análises políticas marxistas "decorrem da genialidade pessoal de Marx, não das categorias e de um

13. SOUZA, 2015, p. 45.

14. EAGLETON, Terry. Marx estava certo. Rio de Janeiro: Nova Fronteira, 2012, p. 98.

15. Idem, p. 101.

16. Idem, p. 98

17. SOUZA, 2015, p. 116 quadro de referência teórico refinado que pode ser aplicado a diversos contextos concretos" ${ }^{\prime 17}$. Ora, um dos pressupostos do materialismo histórico-dialético é justamente o de não aplicar mecanicamente conceitos a diversos contextos, mas que eles devem vir da realidade concreta e material.

Podemos dizer, entretanto, que há o mérito de Jessé Souza de colocar no centro do debate as classes e a desigualdade, em um tempo onde há "o esquecimento da luta de classes e sua substituição por conceitos compósitos que ofuscam 
conflitos e contradições, como nação, cultura, região ou civilização"18. Embora o termo "luta de classes" não seja central no livro, o autor mostra como ela acontece em campos diversos, como a própria ciência (e aqui completamos: não é uma luta somente simbólica). "Luta de classes não é apenas a greve sindical ou a revolução sangrenta nas ruas que todos percebem. Ela é, antes de tudo, o exercício silencioso da exploração construída e consentida socialmente" ${ }^{" 19}$. Isto é, ele mostra o papel da ideologia circulando pela sociedade, circulação essa que passa pelos processos comunicacionais. Qual o papel da comunicação na luta de classes? Como os processos comunicacionais, por um lado, revelam essas lutas, e como, por outro, há encobrimento, dissimulação, simulacro (não no sentido baudrillardiano, claramente)? "Nada mais natural que mercado e Estado constituam a 'semântica possível' de uma luta de classes encoberta, já que nas sociedades modernas a proteção às classes dominadas tem sido historicamente tarefa do Estado" 20 .

Compreender a agenda do Brasil atual, cujos discursos circulam nas redes e ruas, é, de certa forma, pensar o protagonismo do campo da comunicação nesses conflitos, muitas vezes midiatizados. A polarização apaixonada das opiniões vista nas redes, por exemplo, nada mais é que uma expressão da própria luta de classes, com circulação de ideias dominantes (ou hegemônicas). Nessa spreadable media ${ }^{21}$, os fãs não são somente os de novela ou Netflix, mas de figuras de uma direita radical. Como a comunicação pode contribuir para transformar esse cenário? Para além de compreender as hegemonias midiáticas/comunicacionais em jogo, como organizar resistências?

Outro ponto a ser salientado é que os interesses de classe, mais do que nunca, não são alinhados somente local ou nacionalmente, mas a partir de grupos capitalistas transnacionais, inclusive midiáticos, em evidência principalmente nas sociedades consideradas "centrais", algo que é sugerido ao longo de todo o livro de Jessé Souza ao falar em "classes sociais globais", mas não exatamente sistematizado: como as disputas de classes ocorrem entre países considerados "centrais" e outros de "periferia"?

Outro tema que permanecia invisibilizado na teoria social de Jessé Souza em sua trajetória e começa a aparecer (ainda com alguma timidez) em A tolice da inteligência brasileira e no livro anterior, Os batalhadores brasileiros é a questão do trabalho, relacionando-o à questão da acumulação no modo de produção capitalista, por exemplo, ao negar o termo "nova classe média", afirmando se tratar, na verdade, de uma "nova classe trabalhadora".

As condições de trabalho e de exploração dessa mão de obra a aproximam muito do patamar de uma classe trabalhadora precarizada, típica da fase atual do capitalismo sob hegemonia no capital financeiro. Característica dessa fase é a legitimação, na qual muitos creem, de que são patrões de si mesmos, especialmente os que estão na posição de trabalhadores autônomos ou proprietários de pequeno negócio sob a base, quase sempre, de mão de obra familiar ${ }^{22}$.

Isto é, nesse ponto, Souza "descobre" que a violência sofrida pelas classes trabalhadoras não é somente simbólica e questões como exploração, acumulação

18. Idem, p. 163.

19. Idem, p. 233.

20. Idem, p. 243.

21. JENKINS, Henry; GREEN, Joshua; FORD, Sam. Cultura da conexão: Criando valor e significado por meio da mídia propagável. São Paulo: Aleph, 2014.

22. SOUZA, 2015, p. 209 
e precarização do trabalho importam para a compreensão da desigualdade brasileira. Outro ponto levantado pelo autor, principalmente a partir da leitura dos escritos de Bourdieu na Argélia, é a disposição temporal envolvendo as classes, ou seja, como as classes populares possuem senso de urgência em relação ao tempo, havendo pouco tempo para uma leitura (dita) desinteressada, por exemplo. "Em sociedades como a brasileira e a indiana, as classes média e alta verdadeiramente roubam o tempo dos desclassificados incapazes de lutar no mercado competitivo" ${ }^{23}$, reduzindo-os à "energia muscular" - na perspectiva do capital - condenando-os "aos 'trabalhos domésticos', no caso das mulheres, e aos serviços pesados, perigosos ou sujos, no caso dos homens" ${ }^{24}$. Nesse sentido, esse "tempo poupado" ajudaria a reproduzir em larga escala os privilégios de nascimento. Mas pensar o tempo envolve também problemáticas ligadas à teoria do valor, em como são produzidas as riquezas, algo que não aparece no livro de Souza, até mesmo pela própria questão de o autor afirmar, a todo o momento, o afastamento do marxismo. Considerar a dimensão temporal é, como mostra também a pesquisa de Judy Wajcman ${ }^{25}$, demonstrar que há um corte de classe em seu "uso". O modo como um executivo é "pressionado pelo tempo" não é o mesmo da urgência de um atendente de telemarketing, ou, como as disposições temporais afetam os sujeitos de diferentes classes de forma desigual.

Então, a despeito de uma leitura superficial de Marx e um estilo por vezes arrogante na forma da crítica aos autores, o livro de Jessé Souza é imprescindivel para compreendermos o terreno das batalhas sociais onde estamos inseridos em nosso país, onde parte da intelligentsia contribui para reproduzir privilégios históricos. O que há em jogo, portanto, segundo Souza, é a luta entre dois projetos históricos para o Brasil, envolvendo a reprodução dessas estruturas de privilégio ou a verdadeira inclusão da maior parte da população, alijada historicamente dos processos decisórios. Mesmo os últimos trezes anos serem marcados por um "reformismo fraco", com "timidez e fraqueza" 26 , produziu-se "uma reação sem precedentes em uma das sociedades complexas mais perversas e conservadoras da história moderna" ${ }^{27}$. Nesse sentido, a classe média "tradicional" contribui tanto para a legitimação da desigualdade brasileira quanto serve como "tropa de choque do $1 \%$ de endinheirados" ${ }^{2}$. É ela quem sai à rua, como Souza explicita a partir dos movimentos de junho de 2013, "sequestrando as demandas populares do início das manifestações em nome da eterna corrupção só da política - para defender os interesses da classe de endinheirados que as explora" ${ }^{29}$. Essa classe média conservadora, segundo Souza, foi, em todos os casos, "usada como massa de manobra para derrubar os governos de Vargas, Jango e agora Lula-Dilma e conferir o 'apoio popular' e a consequente legitimidade para esses golpes sempre no interesse de meia dúzia de poderosos" ${ }^{30}$. A isso, se juntam elementos antidemocráticos, moralistas, e uma seletividade de indignação.

O que fica claro, pois, é o papel central da mídia hegemônica ao legitimar interesses de classes. "A imprensa é fundamental neste processo, posto que é necessário 'legitimar' o assalto ao princípio da soberania popular como única 
fonte que permite vincular legalidade e legitimidade do regime democrático e representativo" ${ }^{31}$. Em tempos que se prenunciam sombrios, onde pessoas aplaudem e "assistem de longe, bestializados, a um espetáculo o qual, como sempre, vão ter que pagar sem participar do banquete" ${ }^{2}$, precisamos, mais do que nunca, pensar e praticar $^{33}$ formas de resistência e, procurando mostrar o papel da comunicação para a transformação social e superação das desigualdades. Em tempos onde ganham audiência debates sobre "não humanos", precisamos pensar o quanto a realidade brasileira ainda é "desumana”. É nosso dever interferir nesses debates; do contrário, estaremos produzindo uma ciência estéril.

\section{REFERÊNCIAS BIBLIOGRÁFICAS}

\section{BAKHTIN, Mikhail (VOLOCHINOV). Marxismo e Filosofia da Linguagem:} Problemas fundamentais do método sociológico na ciência da linguagem. São Paulo: Hucitec, 2010.

EAGLETON, Terry. Marx estava certo. Rio de Janeiro: Nova Fronteira, 2012. JENKINS, Henry; GREEN, Joshua; FORD, Sam. Cultura da Conexão: Criando valor e significado por meio da mídia propagável. São Paulo: Aleph, 2014.

SCHNEIDER, Marco. Ética e epistemologia: Alerta contra a neutralidade axiológica na pesquisa em comunicação contemporânea. Revista Matrizes, v. 7, n. 2, jul./dez. 2013, p. 11-27.

SODRÉ, Muniz. A ciência do comum: Notas para o método comunicacional. Petrópolis: Vozes, 2014.

SOUZA, Jessé. A construção social da subcidadania. Belo Horizonte: Ed. UFMG, 2003.

A invisibilidade da desigualdade brasileira. Belo Horizonte: Ed. UFMG, 2006.

. A modernização seletiva: Uma reinterpretação do dilema brasileiro. Brasília: Ed. UnB, 2000.

A ralé brasileira: Quem é e como vive. Belo Horizonte. Ed. UFMG, 2009.

- A tolice da inteligência brasileira: Ou como o país se deixa manipular pela elite. São Paulo: Casa da Palavra, 2015.

- Os batalhadores brasileiros: Nova classe média ou nova classe trabalhadora? Belo Horizonte: Ed. UFMG, 2010.

WAJCMAN, Judy. Pressed for Time: The Acceleration of Life in Digital Capitalism. Chicago: Chicago University Press, 2015. 